\title{
Drenagem / secagem de lodo de decantadores de ETAs em manta geotêxtil
}

\author{
Drainage / drying of sludge decanters from WTP on geotextile blanket
}

\author{
Emília Kiyomi Kuroda | Cristiane Silveira | José Gustavo Macedo | Mauro Sérgio Pinheiro Lima \\ Flávia Kawahigashi | Aline Domingues Batista | Sandra Márcia Cesário Pereira da Silva \\ Fernando Fernandes
}

Data de entrada: 14/02/2012 | Data de aprovação: 27/05/2013

DOI: http://dx.doi.org/10.4322/dae.2014.002

Resumo

Uma vez que os leitos de drenagem / secagem com manta geotêxtil têm apresentado resultados promissores no tratamento de lodos de decantadores de ETAs no Brasil, esse estudo avaliou esta técnica em protótipos de escala reduzida e piloto, considerando, além de parâmetros de projeto, aspectos quantitativos e qualitativos do drenados e tortas de lodo produzidos. Pode-se constatar que, para o lodo de estudo, a manta de 600 g.m ${ }^{-2}$ com taxa de aplicação de sólidos - TAS da ordem de 3,0 kg.m-2 apresentou melhor desempenho. A fase de secagem nos ensaios em escala piloto foi favorecida, resultando na extinção da lâmina líquida em 1 dia e teor de sólidos totais após 7 dias de 18,3 \% - teores da mesma ordem de grandeza que as obtidas em técnicas mecânicas. O teste de toxicidade com Artemia salina para o lodo inicial apresentou maior toxicidade, evidenciando a eficácia do sistema de desaguamento.

Palavras-chave: Lodo de decantadores de ETA, taxa de aplicação de sólidos, escalas reduzida e piloto, toxicidade.

\begin{abstract}
Since the bed drain / drying geotextile have shown promising results in the treatment of sludges decanters WTP in Brazil, This study evaluated this technique on prototypes and pilot scale, considering, beyond of design parameters, quantitative and qualitative aspects of the drained and pies sludge produced. Can be verified that for the sludge study, the blanket of $600 \mathrm{gm}-2$ with application rate of solids - TAS of around 3,0 kg.m-2 presented better performance. The drying phase in a pilot scale was favored, resulting in extinction of the blade 1 day and total solids content after 7 days of 18.3\%, and the content of the same order of magnitude as those obtained in mechanical techniques. The toxicity test with Artemia salina for the sludge showed higher initial toxicity, indicating the effectiveness of the dewatering system.
\end{abstract}

Key-words: Sludge decanters of WTP, applied solids rate, reduced and pilot scales experiments, toxicity.

${ }^{*}$ Curriculum dos autores - ver página 34 


\section{Introdução}

Nas Estações de Tratamento de Água - ETAs que adotam o tratamento de água por ciclo completo, composto pela sequência dos processos e operações de coagulação, floculação, sedimentação e filtração, os resíduos são gerados principalmente nas unidades de sedimentação e filtração, e são chamados de lodos de decantadores e águas de lavagem de filtros.

Embora os lodos de decantadores, objeto de estudo deste trabalho, sejam classificados como resíduos sólidos segundo a NBR 10.004 (2004), apresentam a maior parcela em termos de volume na fase líquida. Devido principalmente à grande quantidade de água agregada nos lodos de decantadores, seu transporte possui um custo relativamente elevado, fazendo com que grande parte das ETAs descartem esses resíduos nos corpos de água mais próximos. Segundo Lopes et. al, (2005), o tratamento de lodos de decantadores consiste basicamente na remoção da água livre e intersticial presente no lodo com redução de seu volume, facilitando o manuseio, transporte e disposição final adequada deste resíduo.

Dentre as técnicas de desaguamento tradicionalmente utilizadas, os sistemas naturais (lagoas de lodo e os leitos de drenagem / secagem) têm apresentado vantagens em relação aos sistemas mecânicos (centrífugas, filtros-prensa, prensa desaguadora, filtros a vácuo), devido aos baixos custos de implantação, operação e manutenção, e facilidade operacional, além de serem uma alternativa ambientalmente mais favorável, visto que em sistemas naturais não são utilizados insumos como energia elétrica e produtos químicos. Porém, deve-se considerar que uma limitação dos sistemas naturais é a condição climática.

Visto que no Brasil existem condições favoráveis ao desaguamento natural, Cordeiro (1993) e (2001) iniciou um estudo sobre a modificação dos leitos de secagem tradicionais, que passou a ser chamado Leito de Drenagem. Os resultados dos estudos com os Leitos de Drenagem mostraram uma redução no tempo de remoção da água livre e boa qualidade do drenado produzido, permitindo sua reutilização. Em 2004, Fontana aplicou este modelo de leito de secagem em escala real na ETA do município de Cardoso, SP e conseguiu reproduzir os resultados encontrados em escala de laboratório obtidos anteriormente.

Os resultados promissores encontrados nestas pesquisas combinados com as mudanças nas normas ambientais e as preocupações com a proteção ambiental conduziram a um aumento no número de ETAs que adotam sistemas de tratamento de resíduos no Brasil. Porém, segundo Barroso (2007), os sistemas de desaguamento atualmente existentes no Brasil ainda possuem problemas a serem solucionados, tanto na questão operacional quanto na disposição da torta de lodo final.

Dentro deste contexto, este estudo foi desenvolvido com o objetivo de avaliar o sistema de desaguamento de lodo de decantadores de ETA em leito de drenagem / secagem com uso de manta geotêxtil e ensaios de laboratório em protótipos de escalas reduzida e piloto, considerando os aspectos técnicos de projeto:

- Concepção física: taxa de aplicação de sólidos - TAS e densidade da manta geotêxtil;

- Condições operacionais: lâmina líquida na unidade de drenagem e duração das fases de drenagem e de secagem;

- Eficiência do sistema: caracterização do lodo afluente ao sistema de desaguamento, aspectos quantitativos, qualitativos e de toxicidade da água drenada e da torta de lodo produzidas.

\section{Metodologia}

\section{Ensaios de desaguamento}

Os lodos utilizados nos desaguamentos foram coletados em um dos decantadores convencionais da ETA Cafezal do município de Londrin, PR, que trata água com características predominantemente inorgânicas e utiliza o tratamento por ciclo completo, empregando o cloreto férrico como coagulante químico e cal hidratada como alcalinizante. Como os decantadores são convencionais de fluxo horizontal, sem sistema de remoção de lodo, a limpeza é feita mensalmente com esvaziamento completo da unidade. Assim, para realização dos experimentos nos protótipos de escala reduzida foi realizada apenas uma coleta de lodo de 500 L, no dia 09/09/2010, e para os experimentos em escala piloto uma coleta de 5.000 L no dia 07/10/2010. Ambas as coletas foram realizadas no final da limpeza dos decantadores para obtenção de lodo com maior concentração de sólidos. Os ensaios de desaguamento em protótipos de escala reduzida - Etapa I ti- 
veram como objetivos selecionar, na fase de drenagem, a densidade de manta geotêxtil e respectiva taxa de aplicação de sólidos - TAS (quantidade de sólidos em kg aplicados em 1 $\mathrm{m}^{2}$ de área do leito de drenagem / secagem) mais adequadas à aplicação posterior em escala piloto.

Os ensaios de desaguamento em protótipos de escala piloto - Etapa II tiveram como objetivos avaliar a aplicação dos parâmetros de projeto e de operação selecionados em escala reduzida, considerando a eficiência do sistema de desaguamento quanto aos aspectos quantitativos e qualitativos.

Visando atender a uma condição de demanda operacional crítica passível de aplicação em ETAs de pequeno porte, cada ensaio de desaguamento foi dividido em duas fases distintas e consecutivas: fase de drenagem (até a extinção da lâmina líquida) e fase de secagem, com duração total de 7 dias. Durante a fase de drenagem, todo o lodo drenado foi coletado em frascos de volumes preestabelecidos e acondicionado sob refrigeração para posterior análise. Na escala reduzida a coleta da água drenada foi realizada continuamente em frascos de $100 \mathrm{~mL}$. Na escala piloto, durante os primeiros 20 minutos a água drenada foi coletada em intervalos de 2 minutos, utilizando frascos de $1 \mathrm{~L}$, e em seguida, em inter- valos de 10 minutos até completar 1 hora, e posteriormente a cada hora, utilizando frascos de $500 \mathrm{~mL}$. Para avaliar o impacto da carga de poluição / contaminação gerada pelo lançamento dos lodos drenados em corpos hídricos receptores, considerando o lançamento direto da totalidade do volume drenado foi constituída uma amostra composta dos lodos drenados - Amostra global, utilizando-se $50 \mathrm{~mL}$ das amostras coletadas ao longo do tempo na fase de drenagem.

Devido à facilidade de análise, rápido tempo de resposta e boa correlação com o teor de sólidos totais, expressa por fórmulas empíricas em Cornwell (1987), Cordeiro (1993) e AWWA (1996), o parâmetro de controle de eficiência utilizado para avaliar as unidades de desaguamento foi a turbidez, e para sistematizar os resultados em relação à qualidade do drenado foram estabelecidas duas condições de atendimento:

- Condição I: drenados com valores de turbidez inferiores a $10 \mathrm{uT}$, considerando a possibilidade de reaproveitamento do lodo drenado no sistema de produção de água da própria ETA; - Condição II: drenados com valores de turbidez inferiores a 100 uT, compatíveis com corpos de água doce Classe II, segundo estabelecido pela Resolução 357/05 do Conama, classificação da maioria dos corpos hídricos

\begin{tabular}{|c|c|}
\hline PARÂMETRO & MÉTODO APHA, AWWA e WEF (2005) \\
\hline $\mathrm{pH}$ & Potenciométrico / 4500 \\
\hline Umidade relativa do ar (\%) & Digital \\
\hline Turbidez (uT) & Nefelométrico / 2130 B \\
\hline Cor aparente $(\mathrm{uH})$ & Espectrofotométrico/ $2120 \mathrm{C}$ \\
\hline Cor verdadeira (uH) & $\begin{array}{l}\text { Espectrofotométrico / } 2120 \mathrm{C} \\
\text { Filtrado em membrana com porosidade } 0,45 \mu \mathrm{m}\end{array}$ \\
\hline $\mathrm{DBO}_{5 \mathrm{~d}}, 20^{\circ} \mathrm{C}\left(\mathrm{mg} \cdot \mathrm{L}^{-1}\right)$ & Teste DBO 5 dias a $20^{\circ} \mathrm{C} / 5210 \mathrm{~B}$ \\
\hline $\mathrm{DQO}\left(\mathrm{mg} \cdot \mathrm{L}^{-1}\right)$ & Refluxo fechado / 5220 C \\
\hline Série de sólidos $\left(\mathrm{mg} \cdot \mathrm{L}^{-1}\right)$ & $\begin{array}{l}\text { Sólidos secos a } 103-105^{\circ} \mathrm{C} / 2540 \mathrm{~B} \text {; } \\
\text { Sólidos voláteis incinerados a } 550^{\circ} \mathrm{C} / 2540 \mathrm{E}\end{array}$ \\
\hline Coliformes totais e $E$. coli (NMP/100 mL) $\left(^{*}\right)$ & Substrato cromogênico / colilert / 9223B \\
\hline 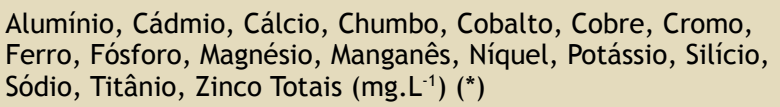 & ICP-OES Plasma/ 3125 \\
\hline
\end{tabular}

(*) Análises realizadas somente no ensaio de desaguamento em escala piloto

Tabela 1- Parâmetros de desempenho e métodos analíticos / equipamentos utilizados nos experimentos 


\begin{tabular}{|c|c|c|c|}
\hline $\begin{array}{l}\text { Densidade } \\
\text { da manta } \\
\left(\mathrm{g} \cdot \mathrm{m}^{-2}\right)\end{array}$ & $\begin{array}{c}\text { Taxas de aplicação } \\
\text { de sólidos - TAS } \\
\left(\mathrm{kg} \cdot \mathrm{m}^{-2}\right)\end{array}$ & $\begin{array}{l}\text { Vazão de } \\
\text { aplicação } \\
\left(\mathrm{mL} \cdot \mathrm{min}^{-1}\right)\end{array}$ & $\begin{array}{l}\text { Tempo de } \\
\text { drenagem } \\
\text { / seca- } \\
\text { gem (d) }\end{array}$ \\
\hline 150 & $2,5 / 5,0 / 10,0$ & \multirow{3}{*}{100} & \multirow{3}{*}{$4-7$} \\
\hline 300 & $1,25 / 2,5 / 5,0$ & & \\
\hline 600 & $1,25 / 2,5 / 5,0$ & & \\
\hline
\end{tabular}

Tabela 2 - Parâmetros de projeto aplicados nos ensaios de desaguamento em escala reduzida - Etapa I

receptores da região.

Os lodos iniciais e os drenados produzidos nos desaguamentos nos protótipos em escala reduzida e piloto foram caracterizados quanto aos parâmetros físicos, químicos e microbiológicos, seguindo procedimentos da APHA, AWWA e WEF (2005) com adaptações, apresentados na Tabela 1. As análises para quantificação dos metais foram realizadas por um laboratório credenciado para prestação de serviços.

\section{Etapa I - Ensaios de desaguamento em protóti- pos de escala reduzida}

Para a realização dos ensaios de desaguamento em escala reduzida, foram construídos 9 unidades de desaguamento, possibilitando assim a utilização de 3 tipos de manta e 3 valores de TAS, totalizando 9 ensaios de desaguamento. A Tabela 2 apresenta os parâmetros de projeto aplicados nos ensaios de desaguamento em escala reduzida.

A unidade de desaguamento em escala reduzida foi constituída por um tubo de PVC DN $100 \mathrm{~mm}$ e $60 \mathrm{~cm}$ de altura com um indicador externo de nível, adaptado a um CAP de PVC com fundo recortado para dispor o leito de drenagem, o qual era composto por uma grelha plástica para suporte da manta geotêxtil. Abaixo do CAP foi fixado um dispositivo de fundo cônico para coleta do drenado.

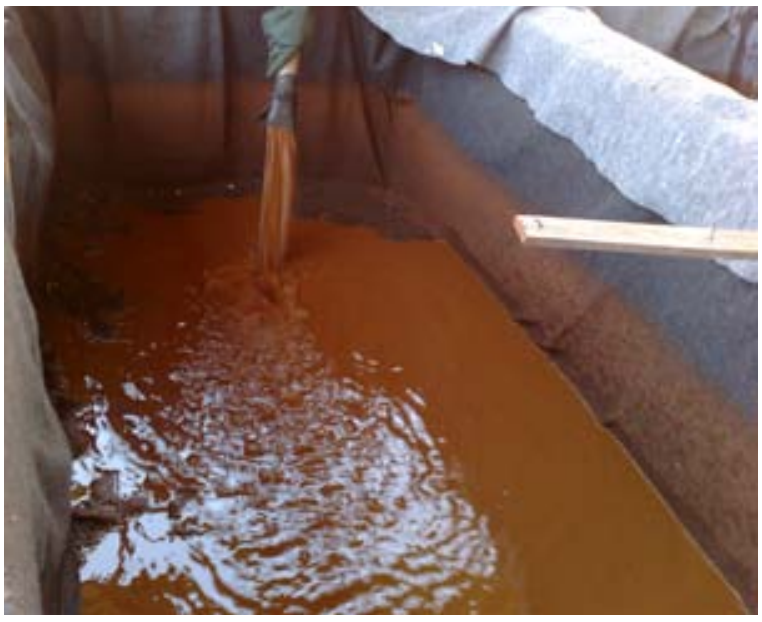

Figura 1 - Foto da unidade de desaguamento protótipo em escala piloto

Etapa II - Ensaios de desaguamento em protótipos de escala piloto

Na Tabela 3 são apresentados os parâmetros de projeto aplicados nos ensaios de desaguamento em escala piloto. O lodo foi aplicado nos leitos através de um caminhão tanque com auxílio de uma bomba.

O sistema em escala piloto (Figura 1) utilizado neste trabalho foi o mesmo utilizado por Silva (2006), composto por duas unidades de desaguamento nas dimensões de $2,5 \mathrm{~m}$ de comprimento e $1 \mathrm{~m}$ de largura, interligadas a duas caixas de fibra de vidro com capacidade de $500 \mathrm{~L}$, para coleta do drenado. $\mathrm{O}$ material de enchimento das unidades de drenagem / secagem foi brita $n^{0} 3$ com altura de 0,20 m.

\section{Testes ecotoxicológicos}

Complementarmente, foram realizados testes ecotoxicológicos com o organismo Artemia salina nas amostras de lodo inicial e amostra global de drenados produzidos no Leito 2 do sistema em escala piloto.

O teste de toxicidade preconiza a exposição

\begin{tabular}{|c|c|c|c|c} 
& Manta $\left(\mathrm{g} \cdot \mathrm{m}^{-2}\right)$ & $\begin{array}{c}\text { Taxa de aplicação de } \\
\text { sólidos - TAS }\left(\mathrm{kg} \cdot \mathrm{m}^{-2}\right)\end{array}$ & $\begin{array}{c}\text { Vazão de aplicação } \\
\left(\text { L.min }{ }^{-1}\right)\end{array}$ & $\begin{array}{c}\text { Tempo de drenagem / } \\
\text { secagem (d) }\end{array}$ \\
\hline Leito 1 & 350 & 3,27 & 30 & $4-7$ \\
\hline Leito 2 & 600 & 2,98 & 30
\end{tabular}

Observe que os valores de vazão de aplicação e tempo de drenagem / secagem é comum aos 2 leitos.

Tabela 3 - Parâmetros de projeto aplicados nos ensaios de desaguamento em escala piloto - Etapa II 
dos organismos à amostra, considerando várias diluições em quadruplicata. Após preparação de todos os tubos com as diluições preestabelecidas, com o auxílio de uma pipeta de Pasteur, adicionou-se de 9 a 12 náuplios de Artemia salina por tubo. Os tubos foram mantidos sob iluminação constante e temperatura de 27 a $30^{\circ} \mathrm{C}$ por $24 \mathrm{~h}$. O controle negativo (branco) foi realizado com a solução salina e o controle positivo, com solução de dicromato de potássio $\left(\mathrm{K}_{2} \mathrm{Cr}_{2} \mathrm{O}_{7}\right)$ em solução salina com concentração de $45 \mathrm{mg} \cdot \mathrm{L}^{-1}$. Após 24 h de exposição, o número de Artemias vivas e mortas em cada tubo foi quantificado para, posteriormente, determinar a concentração da amostra que causou mortalidade de $50 \%$ dos organismos após exposição de $24 \mathrm{~h}$ - $\mathrm{CL}_{50} \mathrm{O}_{24 \mathrm{~h}}$ nas condições do teste. A CL50 $24 \mathrm{~h}$ foi obtida por cálculo estatístico usando o programa Trimmed Spearman-Karber (HAMILTON, et al. 1977) com intervalo de confiança de 95\% e também foi calculada por análise de regressão linear.

\section{Resultados e discussões}

\section{Caracterização do lodo de estudo}

Na Tabela 4 são apresentadas as características físicas, químicas e microbiológicas dos lodos de estudo e os limites máximos dos parâmetros analisados estabelecidos pela Resolução 357/2005 do Conselho Nacional do Meio Ambiente - Co- nama, para enquadramento em corpos de água doce Classe II.

As características do lodo são bastante particulares e variáveis em função das características da água bruta, dos produtos químicos utilizados, dos processos de tratamento adotados e métodos de limpeza dos decantadores (DI BERNARDO \& DANTAS, 2005).

Foi observado que os valores dos parâmetros analisados nos lodos iniciais em estudo apresentaram-se acima do limite aceitável pela legislação. Portanto, sem dúvida, o lançamento desses lodos in natura em corpos de água doce Classe II com as características apresentadas acarretaria impactos negativos ao corpo receptor, o que comprova a necessidade de um tratamento prévio ao descarte no corpo hídrico.

Etapa I - Ensaios de desaguamento em protótipos de escala reduzida

De uma forma geral, as porcentagens de volume de drenado que atenderam às condições estabelecidas foram maiores para as mantas de maior densidade e valores mais elevados de TAS.

Em relação à produção de lodo drenado com valores de turbidez inferiores a $10 \mathrm{uT}$ - Condição I, pôde-se observar que, independentemente dos valores das TAS, as porcentagens de volumes de drenado que atenderam à Condição I foram superiores a 44, 48 e 72 \% para as

\begin{tabular}{|c|c|c|c|c|}
\hline \multirow{2}{*}{ Parâmetro } & \multirow{2}{*}{$\begin{array}{l}\text { Lodo inicial utilizado } \\
\text { na Escala reduzida }\end{array}$} & \multicolumn{2}{|c|}{ Lodo inicial utilizado na Escala piloto } & \multirow{2}{*}{$\begin{array}{c}\text { Limite Conama - } \\
\text { Classe II }\end{array}$} \\
\hline & & Leito 1 & Leito 2 & \\
\hline Turbidez (UT) & 16.900 & 18.200 & 19.500 & 100 \\
\hline Cor aparente $(\mathrm{uH})$ & 65.507 & 56.376 & 67.081 & -- \\
\hline Cor verdadeira $(\mathrm{uH})$ & 36 & 44 & 87 & 75 \\
\hline ST (mg. $\left.\mathrm{L}^{-1}\right)$ & 14.132 & 13.635 & 16.120 & -- \\
\hline $\mathrm{SDT}\left(\mathrm{mg} \cdot \mathrm{L}^{-1}\right)$ & 2.532 & 1.095 & 760 & 500 \\
\hline $\mathrm{DBO}_{5 \mathrm{~d}}, 20^{\circ} \mathrm{C}\left(\mathrm{mg} \mathrm{L}^{-1}\right)$ & 129 & N.A. & N.A. & 5 \\
\hline $\mathrm{DQO}\left(\mathrm{mg} \cdot \mathrm{L}^{-1}\right)$ & 687 & 1.240 & 1.547 & $200 *$ \\
\hline Coliformes totais (NMP/100 mL) & N.A. & N.A. & 141.380 & -- \\
\hline E. coli $(\mathrm{NMP} / 100 \mathrm{~mL})$ & N.A. & N.A. & 4.130 & 1.000 \\
\hline
\end{tabular}

(*) Limite estabelecido pela Resolução $n^{\circ}$ 0070/2009 do Conselho Estadual do Meio Ambiente - CEMA

(--) Limite não estabelecido pela Resolução 357/05 do Conama;

N.A.: não analisado

Tabela 4 - Características dos lodos de estudo e limites da Resolução 357/05 do Conama 


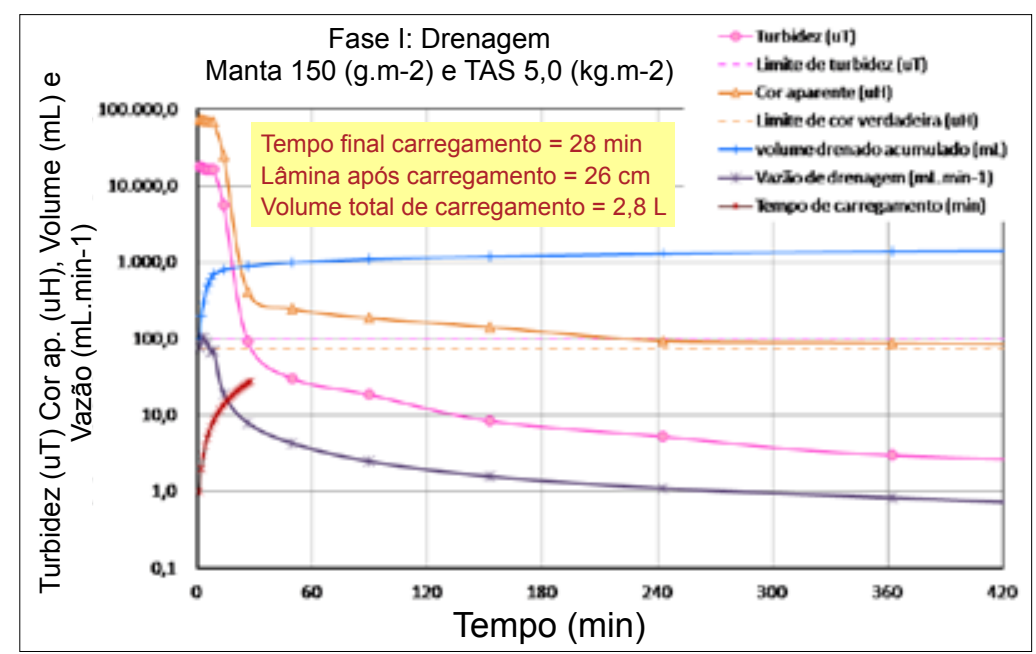

Figura 2 - Resultados da Fase de drenagem para manta geotêxtil de 150 g.m e TAS de 5,0 kg.m $\mathrm{m}^{2}$ / Escala reduzida - Etapa I

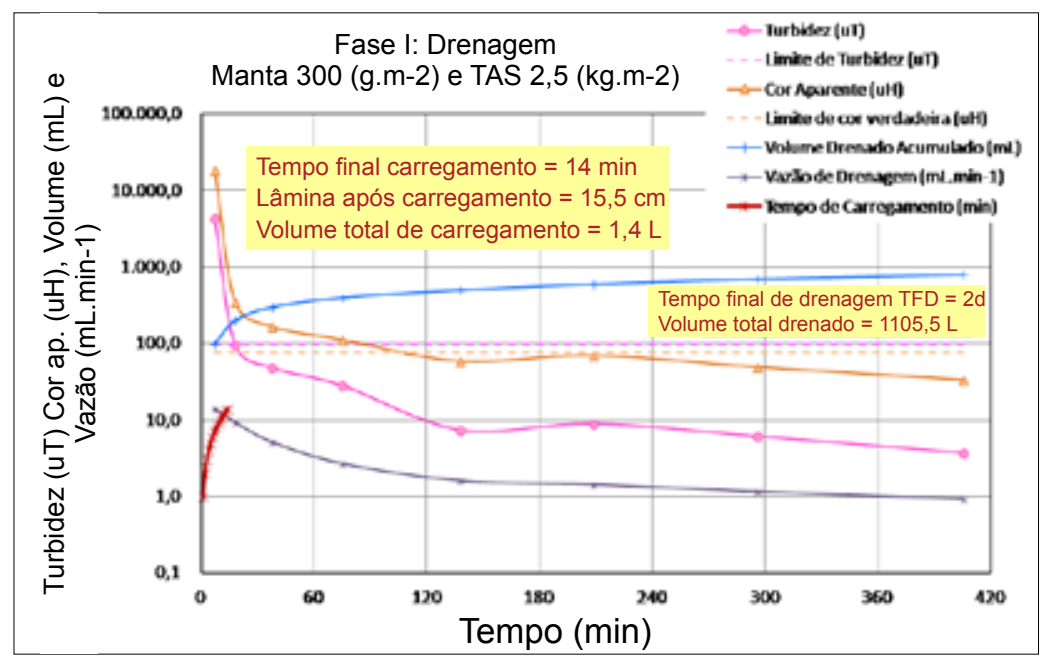

Figura 3 - Resultados da Fase de drenagem para manta geotêxtil de 300 g.m $\mathrm{m}^{-2}$ e TAS de 2,5 kg.m ${ }^{-2}$ / Escala reduzida - Etapa I

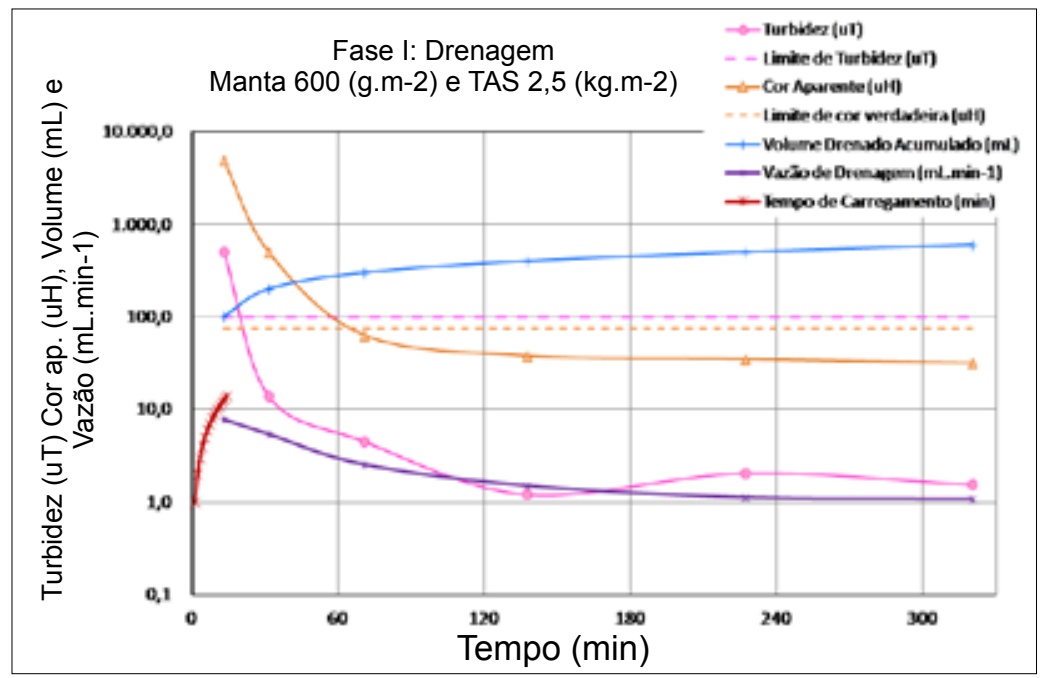

Figura 4 - Resultados da Fase de drenagem para manta geotêxtil de 600 g.m $\mathrm{m}^{-2}$ e TAS de 2,5 kg.m / Escala reduzida - Etapa I 
mantas de 150,300 e 600 g.m² ${ }^{-2}$, respectivamente. Já em relação à Condição II com lodo drenado com valores de turbidez inferiores a $100 \mathrm{uT}$, essas porcentagens foram de 50, $65 \mathrm{e}$ $78 \%$ para as mantas de 150, 300 e 600 g.m ${ }^{-2}$, respectivamente.

Nas Figuras 2 a 4 são apresentados os gráficos dos resultados da fase de drenagem para as mantas geotêxteis de 150, 300 e 600 g.m ${ }^{2}$ com as respectivas TAS que proporcionaram as maiores porcentagens de volume que atenderam às condições I e II.

Para a manta de 150 g.m $\mathrm{m}^{-2}$ e TAS de 5 kg.m ${ }^{-2}$, $78 \%$ do volume de drenado apresentou turbidez inferior a $10 \mathrm{uT}$ - Condição I, e para as mantas de 300 g.m ${ }^{2}$ e 600 g.m - $^{2}$ e TAS de 2,5 $\mathrm{kg} . \mathrm{m}^{-2}$, os volumes de drenado foram respectivamente de 80 e $83 \%$. Com as mesmas TAS as porcentagens de volume de drenado que atenderam a Condição II foram 84, 86 e 87\% para as mantas de 150, 300 e 600 g.m ${ }^{-2}$, respectivamente.

Para avaliar o impacto da carga de poluição gerada pelo lançamento do volume global do drenado em um corpo hídrico receptor classe II, foi constituída uma amostra composta dos drenados - Amostra global e realizada a caracterização físico-química da mesma. As Figuras 5 e 6 correspondem aos resultados de turbidez e DQO da Amostra global dos drenados, respectivamente.

Em relação à turbidez, as amostras globais de drenados que atenderam à Condição II, para corpos de água classe II, foram apenas as da manta de 600 g.m $\mathrm{m}^{2}$, independentemente da

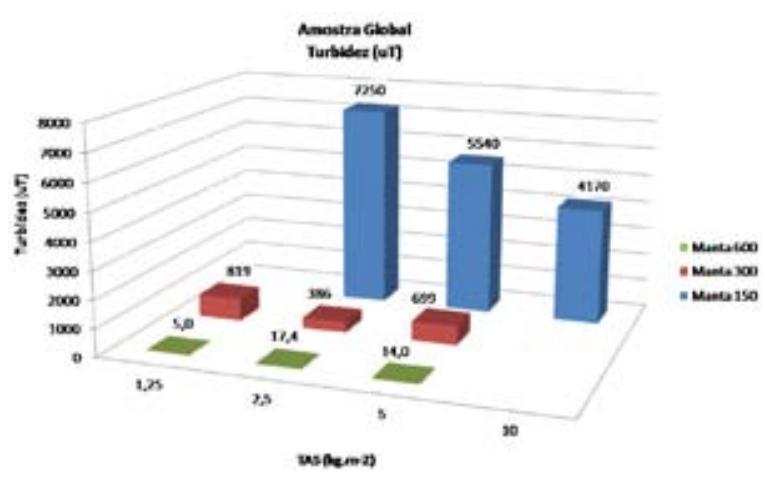

Figura 5 - Turbidez das Amostras globais dos drenados / Escala reduzida - Etapa I
TAS aplicada, apresentando valores de turbidez que variaram de 5 a $14 \mathrm{uT}$.

A Resolução no 0070/2009 do Conselho Estadual do Meio Ambiente - CEMA estabelece o limite de DQO de 200 mg. $\mathrm{L}^{-1}$ e, como se pode observar na Figura 6, independentemente das TAS, somente as mantas de 300 e 600 g.m ${ }^{-2}$ foram eficientes para enquadramento nesta legislação.

\section{Etapa II - Ensaios de desaguamento em pro- tótipos de escala piloto}

Os parâmetros de projeto aplicados nos ensaios de desaguamento em escala piloto (Tabela 3) foram selecionados, considerando os melhores resultados obtidos na Etapa I (mantas de 300 e 600 g.m ${ }^{-2}$ e TAS médio de 2,5 kg.m-2). No entanto, os valores de TAS resultantes do experimento em escala piloto foram de 3,3 kg. $\mathrm{m}^{-2}$ no Leito 1 e 2,98 kg.m ${ }^{-2}$ no Leito 2 .

Em relação à produção de lodo drenado com valores de turbidez inferiores a $10 \mathrm{uT}$ - Condição I, pôde-se observar que as porcentagens de volumes de lodo drenado que atenderam a este limite foram superiores a 82 e $80 \%$ para as mantas 350 e 600 g.m ${ }^{-2}$, respectivamente. Já para a Condição II, essas porcentagens foram de $94,1 \%$ e $90 \%$ para as mantas de 350 e 600 g.m $\mathrm{m}^{-2}$, respectivamente.

Durante os ensaios em escala piloto, os valores médios de temperatura e umidade do ar variaram em torno de $28^{\circ} \mathrm{C}$ e $50 \%$, respectivamente, e não houve ocorrência de precipitação intensa, diferente do ocorrido na escala reduzida, em que os valores médios de tem-

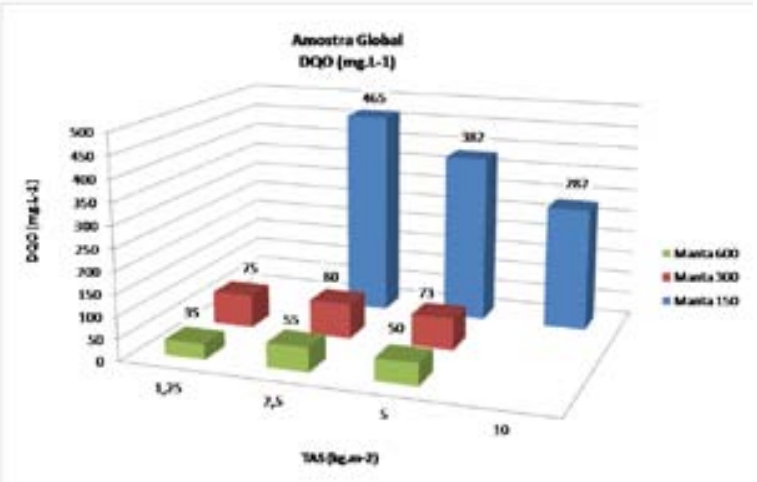

Figura 6 - DQO das Amostras globais dos drenados / Escala reduzida - Etapa I 


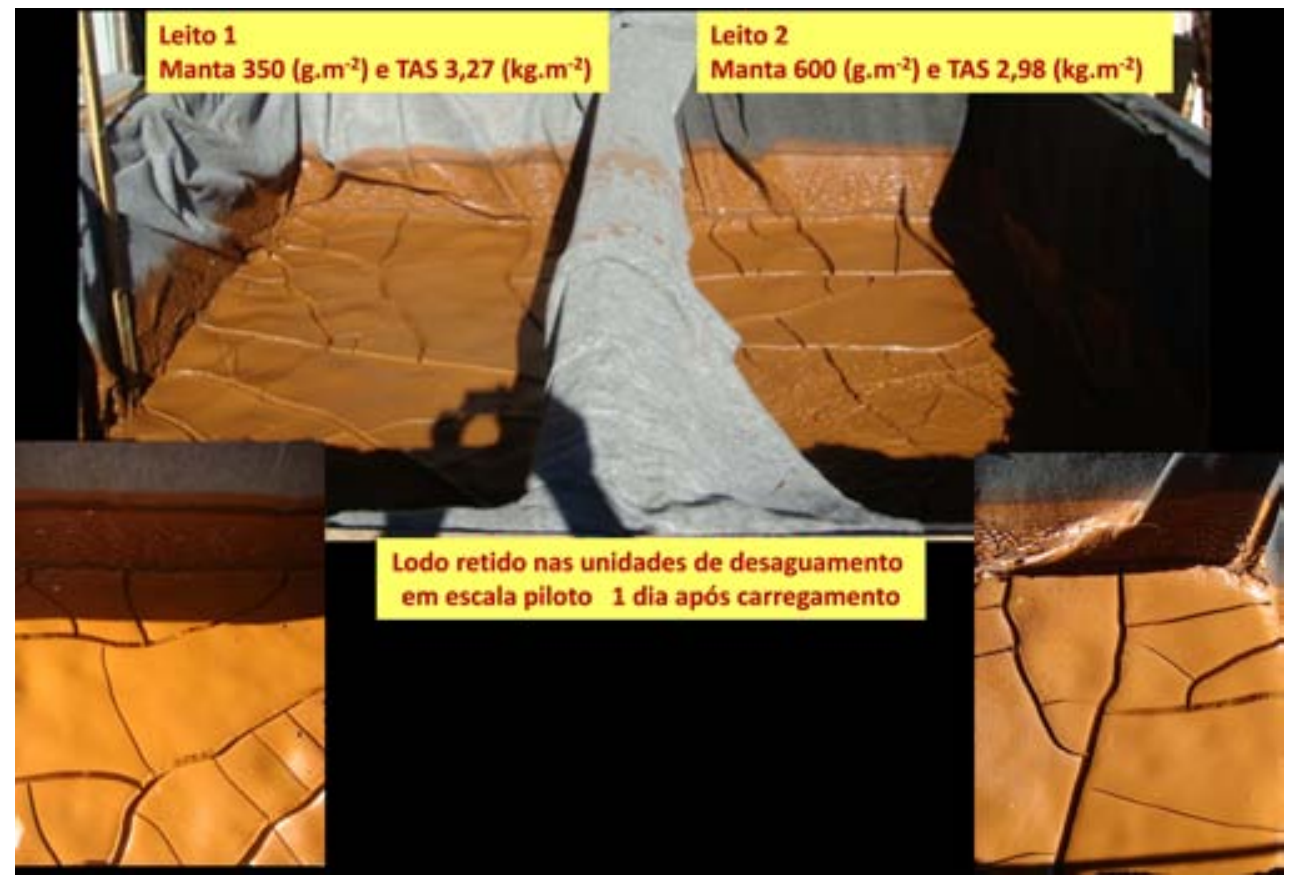

Figura 7 - Foto das unidades de desaguamento em escala piloto - Etapa II, 1 dia após o carregamento

peratura e umidade do ar variaram em torno de $19,2^{\circ} \mathrm{C}$ e $87,5 \%$, respectivamente, com precipitação intensa nos primeiros 2 dias. Esses dados comprovam que além do fator de escala, as condições climáticas na fase de secagem influenciam de forma significativa, uma vez que na escala reduzida a extinção da lâmina líquida para concepção similar ocorreu somente após 2 dias e na escala piloto deu-se em 1 dia. $\mathrm{Na}$ Figura 7 é apresentada uma foto das unidades de desaguamento - Leito 1 e 2 em escala piloto, com extinção da lâmina líquida 1 dia após o carregamento.

A Tabela 5 (pag. 32) mostra os resultados da quantificação de metais no lodo inicial e nas amostras globais dos drenados dos Leitos 1 e 2 .

Como se pôde observar, vários metais analisados apresentaram elevadas concentrações no lodo inicial e superiores aos limites estabelecidos pela Resolução 357/05 para corpos de água doce Classe II, especialmente em relação ao ferro e ao alumínio devido principalmente ao uso do coagulante. Vale ressaltar que os limites máximos estabelecidos pela Resolução 357/05 do Conama referem-se em sua maioria à fração dissolvida do metal, enquanto os valores no lodo inicial e nas amostras globais referem-se à fração total. No entanto, constatou-se que o desaguamento em leito de drenagem / secagem com manta geotêxtil reduziu significativamente as concentrações de metais.

Além disso, os valores limites estabelecidos pela Resolução 357/05 apresentados neste trabalho estão relacionados às condições de enquadramento do corpo de água doce Classe II e não ao lançamento de efluentes. Assim, a análise dos resultados das amostras globais constitui uma situação desfavorável de atendimento, uma vez que o fator de diluição não foi considerado nessas análises e discussões.

Na Figura 8 (pag. 32) são apresentados os gráficos dos resultados da fase de drenagem e

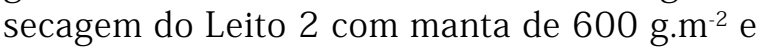
TAS da ordem de 3,0 kg.m ${ }^{-2}$.

A escala piloto favoreceu a perda de umidade no lodo retido, permitindo assim verificar que após 7 dias de secagem a torta de lodo do Leito 2 apresentou teor de sólidos totais de $18,3 \%$, teores da mesma ordem de grandeza que as obtidas em técnicas mecânicas.

Considerando os aspectos quantitativos e qualitativos dos lodos drenados produzidos, tempos requeridos para extinção da lâmina líquida e duração das fases de secagem para os diferentes tipos / densidade de manta geotêxtil e TAS aplicados nos ensaios de desa- 


\section{Artigo Técnico}

\begin{tabular}{|c|c|c|c|c|}
\hline \multirow{2}{*}{ METAIS } & \multirow{2}{*}{ Lodo inicial } & \multirow{2}{*}{$\begin{array}{c}\text { Amostra global } \\
\text { Leito } 1\end{array}$} & \multirow{2}{*}{$\begin{array}{c}\text { Amostra global } \\
\text { Leito } 2\end{array}$} & \multirow{2}{*}{ Limite Conama - Classe II } \\
\hline & & & & \\
\hline AlumínioTotal (mg.L-1 $)$ & 795,4 & 0,10 & 0,07 & 0,1 * \\
\hline Cádmio Total $\left(\mathrm{mg} \cdot \mathrm{L}^{-1}\right)$ & N.D & N.D & N.D & 0,001 \\
\hline Cálcio Total (mg.L $\mathrm{L}^{-1}$ ) & 80,85 & 22,92 & 21,66 & -- \\
\hline Chumbo Total (mg. $\mathrm{L}^{-1}$ ) & N.D & N.D & N.D & 0,01 \\
\hline Cobalto Total (mg. $\mathrm{L}^{-1}$ ) & $<$ L.D & $<$ L.D & $<$ L.D & 0,05 \\
\hline Cobre Total (mg.L-1) & 2,84 & 0,02 & 0,0013 & 0,009 * \\
\hline Cromo Total $\left(\mathrm{mg} . \mathrm{L}^{-1}\right)$ & 2,26 & $<$ L.D & $<$ L.D & 0,05 \\
\hline Ferro Total $\left(\mathrm{mg} \cdot \mathrm{L}^{-1}\right)$ & $2.606,0$ & 0,21 & 0,07 & 0,3 * \\
\hline Fósforo Total (mg.L-1) & 6,90 & N.D & N.D & 0,03 \\
\hline Magnésio Total (mg.L-1) & 20,38 & 4,60 & 4,76 & -- \\
\hline Manganês Total (mg.L-1) & 35,63 & 0,21 & 0,20 & 0,1 \\
\hline Níquel Total $\left(\mathrm{mg} \cdot \mathrm{L}^{-1}\right)$ & N.D & N.D & N.D & 0,025 \\
\hline Potássio Total $\left(\mathrm{mg} \cdot \mathrm{L}^{-1}\right)$ & 0,30 & 3,0 & 2,80 & -- \\
\hline Silício Total (mg.L-1) & 317,10 & 5,17 & 5,27 & -- \\
\hline Sódio Total (mg.L-1) & 1,0 & 3,50 & 3,10 & -- \\
\hline Titânio Total (mg. $\left.\mathrm{L}^{-1}\right)$ & 55,10 & N.D & N.D & -- \\
\hline Zinco Total (mg. $\left.\mathrm{L}^{-1}\right)$ & 2,19 & $<$ L.D & $<$ L.D & 0,18 \\
\hline
\end{tabular}

$<$ L.Q - Abaixo do limite de quantificação / N.D - Não detectado / - - limite não estabelecido pela Resolução

* valor referente ao composto na forma dissolvida

Tabela 5 - Resultados da quantificação de metais no lodo inicial e amostras globais dos drenados produzidos nos ensaios em escala piloto - Etapa II

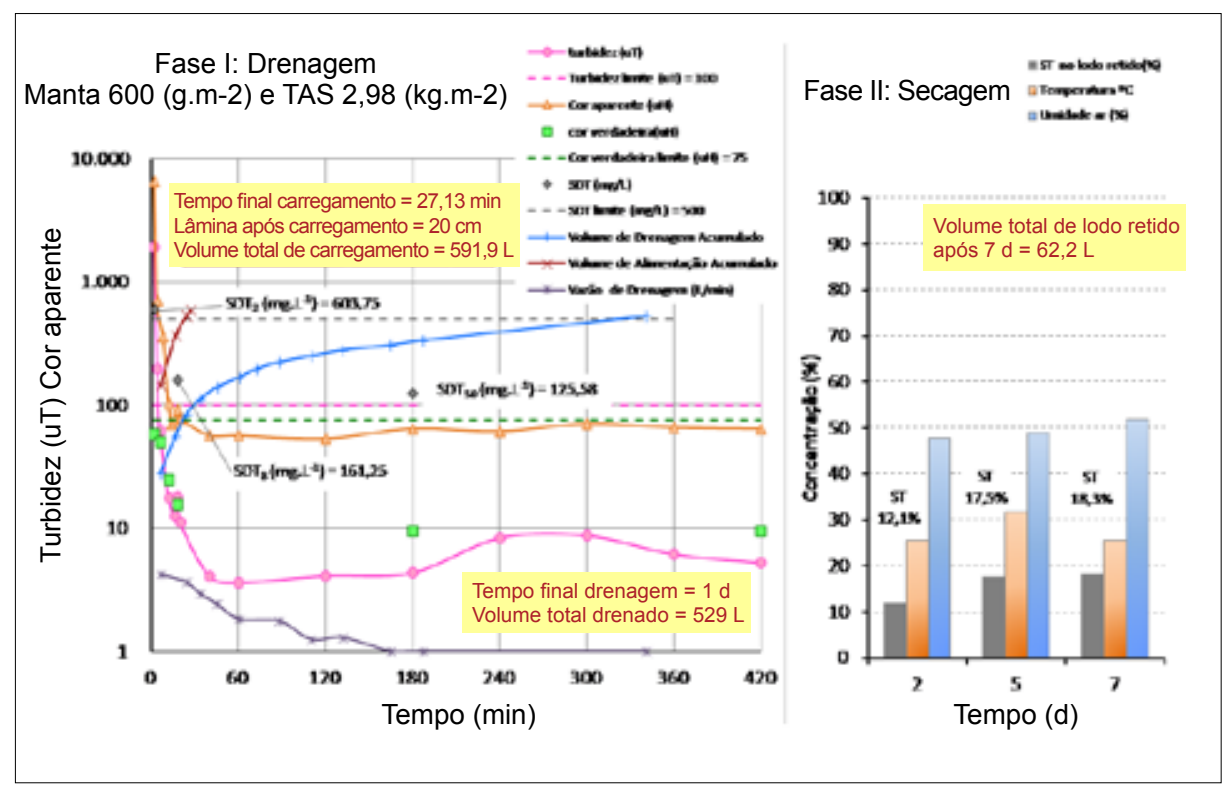

Figura 8 - Resultados da fase de drenagem e secagem no Leito 2/ Escala piloto - Etapa II 


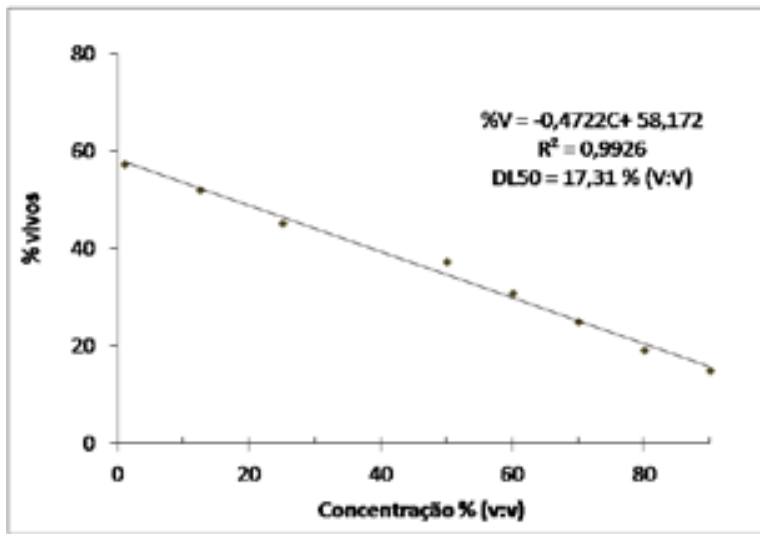

Figura 9 - CL50 do lodo inicial

guamento em protótipos de escalas reduzida e piloto, pode-se constatar que, para o lodo de estudo em questão, a manta de 600 g.m ${ }^{-2}$ com TAS da ordem de 3,0 kg. $\mathrm{m}^{-2}$ apresentou melhor desempenho. Os resultados da Etapa II em escala piloto, especialmente em relação ao tempo de extinção da lâmina líquida, indicaram ainda a possibilidade de aplicação de valores mais elevados de TAS.

Os testes ecotoxicológicos foram introduzidos na Resolução 357/2005 do Conama. No Capítulo IV desta resolução, no que diz respeito às condições e padrões de lançamento de efluentes, é estabelecido nos $\S 1$ e 2 do Artigo 34, que o efluente não deverá causar ou possuir potencial para causar efeitos tóxicos aos organismos aquáticos no corpo receptor, e que os critérios de toxicidade devem-se basear em resultados de ensaios ecotoxicológicos padronizados, utilizando organismos aquáticos.

O teste de toxicidade realizado com o lodo inicial e a amostra global dos drenados do Leito 2 revelaram que o lodo inicial apresenta maior toxicidade frente ao microcrustáceo $\mathrm{Ar}$ temia salina em comparação com a amostra global, provavelmente devido à presença de metais e resíduos de produtos utilizados durante o tratamento de água.

As Figuras 9 e 10 mostram os resultados da CL50 para o lodo inicial e para a amostra global do Leito 2. Como se pode observar, a CL50 da amostra global do Leito 2 foi de 70,49\% (v/v), enquanto a do lodo inicial foi $17,31 \%$ $(\mathrm{v} / \mathrm{v})$, o que comprova a maior toxicidade do lodo inicial e evidencia a eficácia do sistema de desaguamento.

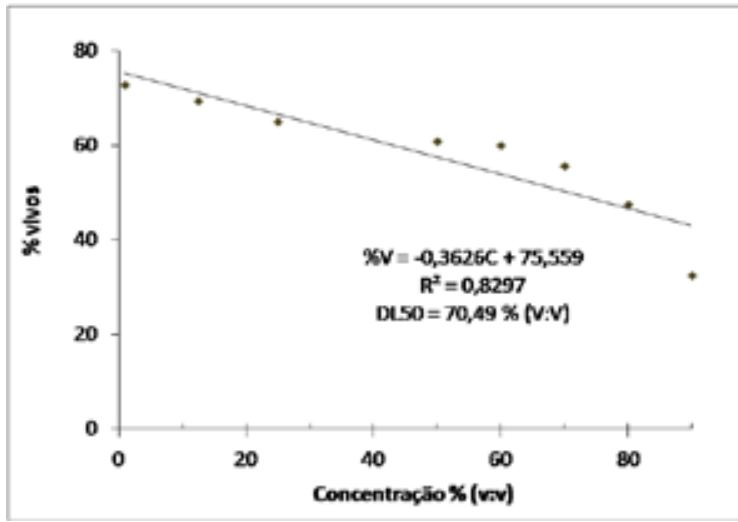

Figura 10 - CL50 da amostra global dos drenados do Leito 2

\section{Conclusões}

Com este estudo, foi possível verificar que:

- O desaguamento de lodo de decantadores de ETAs por leito de drenagem com mantas geotêxteis mostrou ser um processo natural de desaguamento eficiente e passível de aplicação em ETAs de pequeno porte, além de econômico, devido ao baixo consumo de energia ou adição de produtos químicos;

- Os resultados obtidos no protótipo da unidade de drenagem em escala reduzida puderam ser reproduzidos nos ensaios realizados na unidade em escala piloto, o que comprova que ensaios de laboratório em protótipo de escala reduzida podem fornecer subsídios e parâmetros de projeto importantes para uso em projetos de maior escala;

- Considerando os aspectos quantitativos e qualitativos dos lodos drenados produzidos, tempos requeridos para extinção da lâmina líquida e duração das fases de secagem para os diferentes tipos / densidade de manta geotêxtil e TAS aplicados nos ensaios de desaguamento em protótipos de escalas reduzida e piloto, pode-se constatar que, para o lodo de estudo em questão, a manta de 600 g.m ${ }^{-2}$ com TAS da ordem de 3,0 kg.m ${ }^{-2}$ apresentou melhor desempenho. Os resultados da Etapa II em escala piloto, especialmente em relação ao tempo de extinção da lâmina líquida, indicaram ainda a possibilidade de aplicação de valores mais elevados de TAS; - Pôde-se constatar que a perda de umidade nos ensaios em escala piloto foi favorecida, resultando na extinção da lâmina líquida em 1 dia e teor de sólidos totais de 18,3\%,7 dias após o carregamento, teores da mesma ordem de grandeza que as obtidas em técnicas mecânicas;

- Comprovou-se que o desaguamento de lodo de ETA por leito de drenagem / secagem com manta 
geotêxtil reduz consideravelmente a quantidade de metais nos drenados, bem como a toxicidade destes.

\section{Referências Bibliográficas}

ASSOCIAÇÃO BRASILEIRA DE NORMAS TÉCNICAS - ABNT. NBR 10.004 - Resíduos sólidos - Classificação, Rio de Janeiro, 2004.

APHA, AWWA, WEF, Standard Methods For The Examination Of Water \& Wastewater 21st Edition, 2005.

BARROSO, M. M. Influência das micro e macropropriedades dos lodos de Estações de Tratamento de Águas nos Desaguamentos por Leito de Drenagem. Tese de Doutorado, Universidade de São Paulo, 2007.

BRASIL. Conselho Nacional do Meio Ambiente - CONAMA. Resolução n ${ }^{\circ} 357$ de 17 de março de 2005. Dispõe sobre a classificação dos corpos de água e diretrizes ambientais para o seu enquadramento, bem como estabelece as condições e padrões de lançamento de efluentes, e dá outras providências. Brasília, DF, 2005.

CORNWELL, D. A. Water treatment plant waste management. Denver. Environmental Engineering \& Technology, Inc., AWWA Resarch Foundation, 1987.

CORDEIRO, J.S. O problema dos lodos gerados em decantadores de estações de tratamento de água. Tese de Doutorado em Hidráulica e SaneamentoEscola de Engenharia de São Carlos, Universidade de São Paulo, 1993.

CORDEIRO, J.S. Processamento de lodos de Estações de Tratamento de Água (ETAs). (Capítulo V). Coordenador: ANDREOLI, C.V. Resíduos sólidos do saneamento: Processamento, reciclagem e disposição final. Rio de Janeiro: ABES. Projeto PROSAB 2, 2001.

DI BERNARDO, L., DANTAS, A. D. B. Métodos e técnicas de tratamento de água - Volume I e II, Rima Editora, São Carlos - SP, 2005.

FONTANA, A. O. Sistema de Leito de Drenagem e Sedimentador como solução para redução de volume de decantadores e reúso de água de lavagem de filtros - Estudo de Caso - ETA Cardoso. Dissertação de Mestrado, Universidade Federal de São Carlos, 2004.

HAMILTON, M.A.; RUSSO, R.C.; THURSTON, R.V.
Trimmed Spearman-Karber Method for Estimating Median Lethal Concentration in Toxicity Bioassays. Environmental Science \& Technology, Easton, v.11, n.7, 1977.

LOPES, L. N. A.; MACHADO, L. C. G. T.; LIMA, R. F.; PEREIRA, J. A. R. Avaliação do desaguamento de lodo de ETA em leito de secagem. $23^{\circ}$ Congresso Brasileiro de Engenharia Sanitária e Ambiental Campo Grande, 2005.

PARANÁ. Conselho Estadual do Meio Ambiente. Resolução 0070/2009 - CEMA. Dispõe sobre o licenciamento ambiental, estabelece condições e critérios e dá outras providências para Empreendimentos Industriais. Curitiba, 2009.

SILVA, R. C. Avaliação técnica e econômica de sistema alternativo para redução de volume de lodo gerado em Estações de Tratamento de Água (ETAs) de pequeno porte. Trabalho de Conclusão de Curso apresentado ao Curso de Graduação em Engenharia Civil da Universidade Estadual de Londrina, 2006.

SOBRE OS AUTORES

Emília Kiyomi Kuroda*

Engenheira Civil pela Escola de Engenharia de São Carlos - EESC-USP. Mestre e Doutora em Hidráulica e Saneamento pela mesma instituição. Pós-doutora pela Meijo University Japão. Professora do Depto de Construção Civil - CTU da UEL.

Cristiane Silveira

Mestre em Engenharia de Edificações e Saneamento na Universidade Estadual de Londrina - UEL. Tecnóloga em Gerenciamento Ambiental pela Universidade Tecnológica Federal do Paraná UTFPR.

José Gustavo Macedo

Engenheiro Civil pela Universidade Estadual de Londrina - UEL. Mauro Sérgio Pinheiro Lima

Engenheiro Civil pela Universidade Estadual de Londrina - UEL. Flávia Kawahigashi

Química. Mestranda em Engenharia de Edificações e Saneamento do Depto de Construção Civil - CTU da UEL.

Aline Domingues Batista

Aluna de Graduação em Química na Universidade Estadual de Londrina - UEL.

Sandra Márcia Cesário Pereira da Silva

Doutora em Engenharia Civil pela Escola Politécnica da USP. Mestre em Hidráulica e Saneamento pela Escola de Engenharia de São Carlos - EESC-USP. Engenheira Civil pela Universidade Estadual de Londrina - UEL.

Fernando Fernandes

Doutor em Engenharia Civil pela Unicamp. Professor do Depto de Construção Civil - CTU da UEL .

*Endereço para correspondência: Rodovia Celso Garcia Cid; Pr 445; Km 380, Londrina, PR, Brasil. CEP: 86055-900.

Tel: +55 (43) 3371-4815

E-mail: ekkuroda@uel.br 


\section{E você achando que $100 \%$ fosse 0 máximo que alguém pudesse se dedicar.}

Sabesp 300\%: $100 \%$ de água tratada, $100 \%$ de esgoto coletado e $100 \%$ de esgoto tratado.

0 saneamento transforma a vida das pessoas. Por isso, não medimos esforç̧os para levar, até 2014, 0 Sabesp $300 \%$ para todos os municipios do interior atendidos pela Sabesp. E, até 2018, para todas as outras cidades atendidas por nós. Saiba mais acessando www.sabesp.com.br.

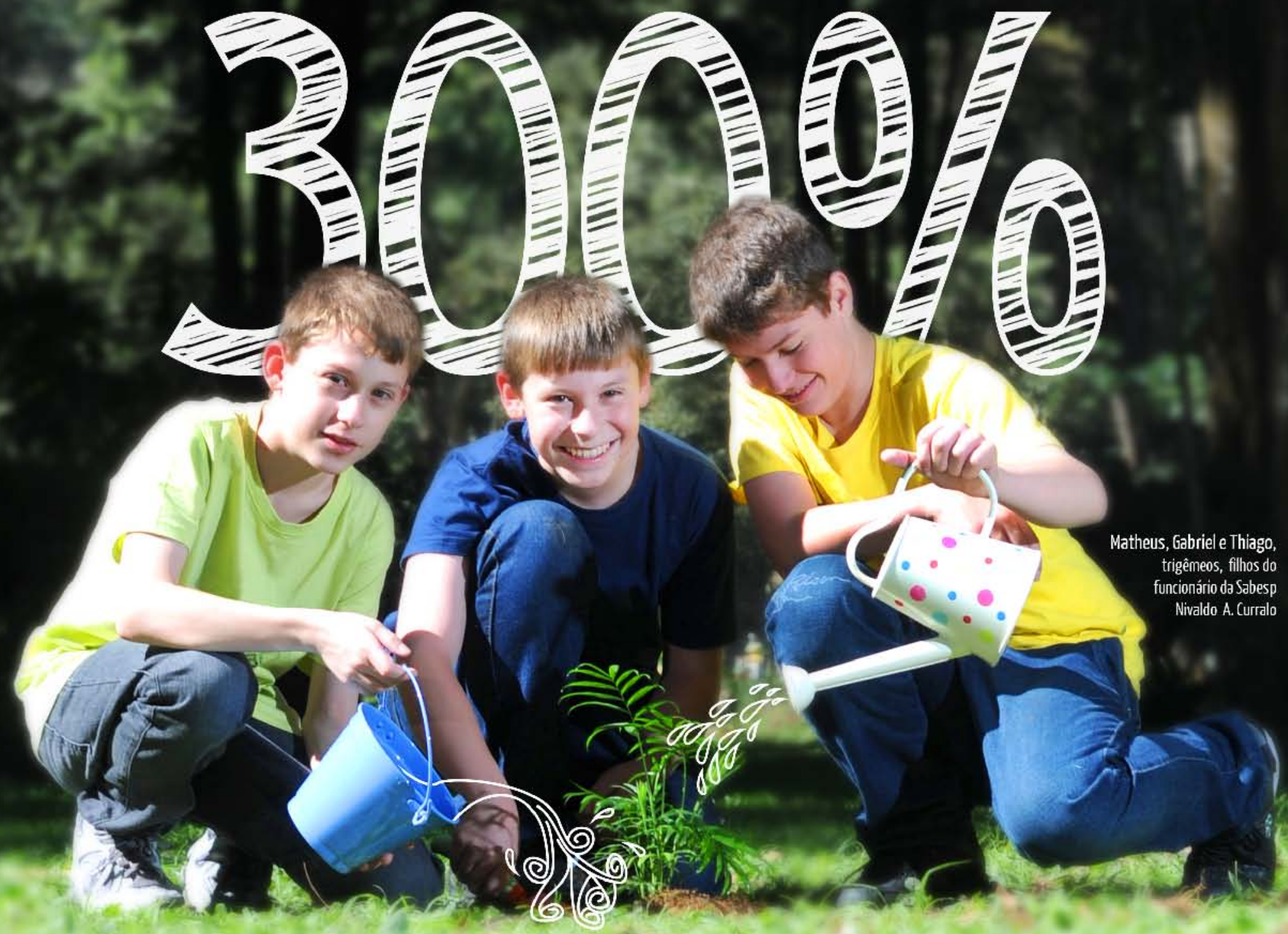

\section{Sabesp.}

Transformando vidas. 